\title{
Effect of ammonia on Ta filaments in the hot wire CVD process
}

\author{
V. Verlaan ${ }^{\text {a }}$, C.H.M. van der Werf ${ }^{\text {a }}$, C.J. Oliphant ${ }^{b, c}$, R. Bakker ${ }^{a}$, Z.S. Houweling ${ }^{\text {a }}$, R.E.I. Schropp ${ }^{\text {a,* }}$ \\ a Utrecht University, Faculty of Science, Department of Physics and Astronomy, Nanophotonics-Physics of Devices, P.0. Box 80,000, 3508 TA Utrecht, The Netherlands \\ b National Centre for Nano-Structured Materials, CSIR, P.O. Box 395, Pretoria, 0001, South Africa \\ c Department of Physics, University of the Western Cape, Private Bag X17, Bellville 7535, South Africa
}

\section{A R T I C L E I N F O}

Available online $\mathrm{xxxx}$

Keywords:

Hot wire CVD

Ta alloys

Filament aging

\begin{abstract}
A B S T R A C T
The exposure of Ta filaments to a pure $\mathrm{NH}_{3}$ ambient in a hot wire chemical vapour deposition (HWCVD) reactor affects the resistance of the wires. For filament temperatures below $1950{ }^{\circ} \mathrm{C}$ the resistance increases over time, which is probably caused by in-diffusion of $\mathrm{N}$ atoms. Using the filaments in a mixed $\mathrm{SiH}_{4}$ and $\mathrm{NH}_{3}$ atmosphere (under $\mathrm{SiN}_{\mathrm{x}}$ deposition conditions) the filaments are hardly affected. Only at the "cold" parts near the electrical contact $\mathrm{SiN}_{\mathrm{x}}$ deposition on the Ta filaments is observed. X-ray diffraction patterns and cross-section microscope images reveal that in $\mathrm{CH}_{4}, \mathrm{H}_{2}$ and $\mathrm{NH}_{3}$ ambient the $\mathrm{TaC}_{0.275} \mathrm{~N}_{0.218}$ phase is formed on the surface of the filament. Annealing of these filaments at $2000{ }^{\circ} \mathrm{C}$ causes the TaC0.275N0.218 structure to separate into $\mathrm{Ta}$ and $\mathrm{Ta}_{2} \mathrm{C}$ phases.
\end{abstract}

(c) 2009 Elsevier B.V. All rights reserved.

\section{Introduction}

In the hot wire chemical vapor deposition (HWCVD) technique the source gasses are decomposed by resistively heated filaments (between 1500 and $2500{ }^{\circ} \mathrm{C}$ ) The source gasses are not only decomposed at the filament, but also interact with the filaments to form alloys. The influence of the source gasses on the filaments is often called "filament aging" and it creates unstable deposition conditions. As a result, this "filament aging" is currently one of the main challenges for commercial implementations of the HWCVD process. This effect is known to occur for silane $\left(\mathrm{SiH}_{4}\right)$ and is therefore intensively studied [1-6]. Although ammonia $\left(\mathrm{NH}_{3}\right)$ is extensively used in many HWCVD processes as in carbon nitride $\left(\mathrm{CN}_{\mathrm{x}}\right)[7,8]$, silicon nitride $\left(\mathrm{SiN}_{\mathrm{x}}\right)[9,10]$ and carbon nanotubes (CNTs) [11] depositions, surprisingly little is known about the influence of $\mathrm{NH}_{3}$ on the filaments. We therefore make a first attempt to describe the effects of pure $\mathrm{NH}_{3}$ on hot Ta filaments and that of $\mathrm{NH}_{3}$ in combination with silane $\left(\mathrm{SiH}_{4}\right)$ and methane $\left(\mathrm{CH}_{4}\right)$.

\section{Experimental details}

For this research $99.9 \%$ pure Ta filaments with a diameter of $0.30 \mathrm{~mm}$ are placed in two reactors: the PASTA [12] and the CANTOR [13]. The evolution of the wire resistance during deposition was monitored by keeping the current through the wires constant (within 1\%) and measuring the voltage by a Keithley 2000 multimeter. After the depositions, cross-sections of the filaments are made by cutting

\footnotetext{
* Corresponding author.

E-mail address: r.e.i.schropp@uu.nl (R.E.I. Schropp).
}

the filaments with a diamond saw and several polishing steps. The cross-sections were investigated by Scanning Electron Microscopy (SEM), Back Scatter Electron (BSE) analysis and Energy Dispersive X-ray (EDX) measurements. The wire surface was studied by X-Ray Diffraction (XRD).

\section{Results and discussions}

\subsection{Effect of pure ammonia}

Fig. 1 (a) shows the voltage over a $14 \mathrm{~cm}$ long Ta wire in a pure $\mathrm{NH}_{3}$ atmosphere of $20 \mathrm{~Pa}$ for various values of the current through the wires. For currents smaller than 6.A $\left(\sim 1950^{\circ} \mathrm{C}\right)$ the voltage increases with time. Since the current was maintained constant during one measurement this means that the resistance moves to larger values. Fig. 1(b) shows a BSE SEM image of a filament after being exposed to a pure $\mathrm{NH}_{3}$ atmosphere (20 Pa using various currents below $6 \mathrm{~A}$ ). 3 regions are distinguishable which are indicated by 1,2 and 3 . It shows that the surface of the wire has roughened. Region 2 reveals a different (more fractured) structure compared to regions 1 and 3. XRD analysis shows no indication of crystalline regions on the surface other than Ta. Furthermore, EDX analysis shows no detectable amounts of $\mathrm{N}$ atoms in any of the three regions after cooling down to room temperature.

The phase diagram of $\mathrm{Ta}$ and $\mathrm{N}$ shows that $\mathrm{N}$ atoms can be dissolved in Ta. The solvability is almost zero at room temperature but increases with increasing temperature to allow as much as 6 at.\% $\mathrm{N}$ atoms to be dissolved in the Ta filament. Inward diffusion of $\mathrm{N}$ atoms from the surface to the bulk of the filaments may cause the increase in resistance with time, at temperatures below $1950{ }^{\circ} \mathrm{C}$. After the power to the filaments is switched off there is a sudden drop in filament temperature. One possible explanation of this difference in structure is 

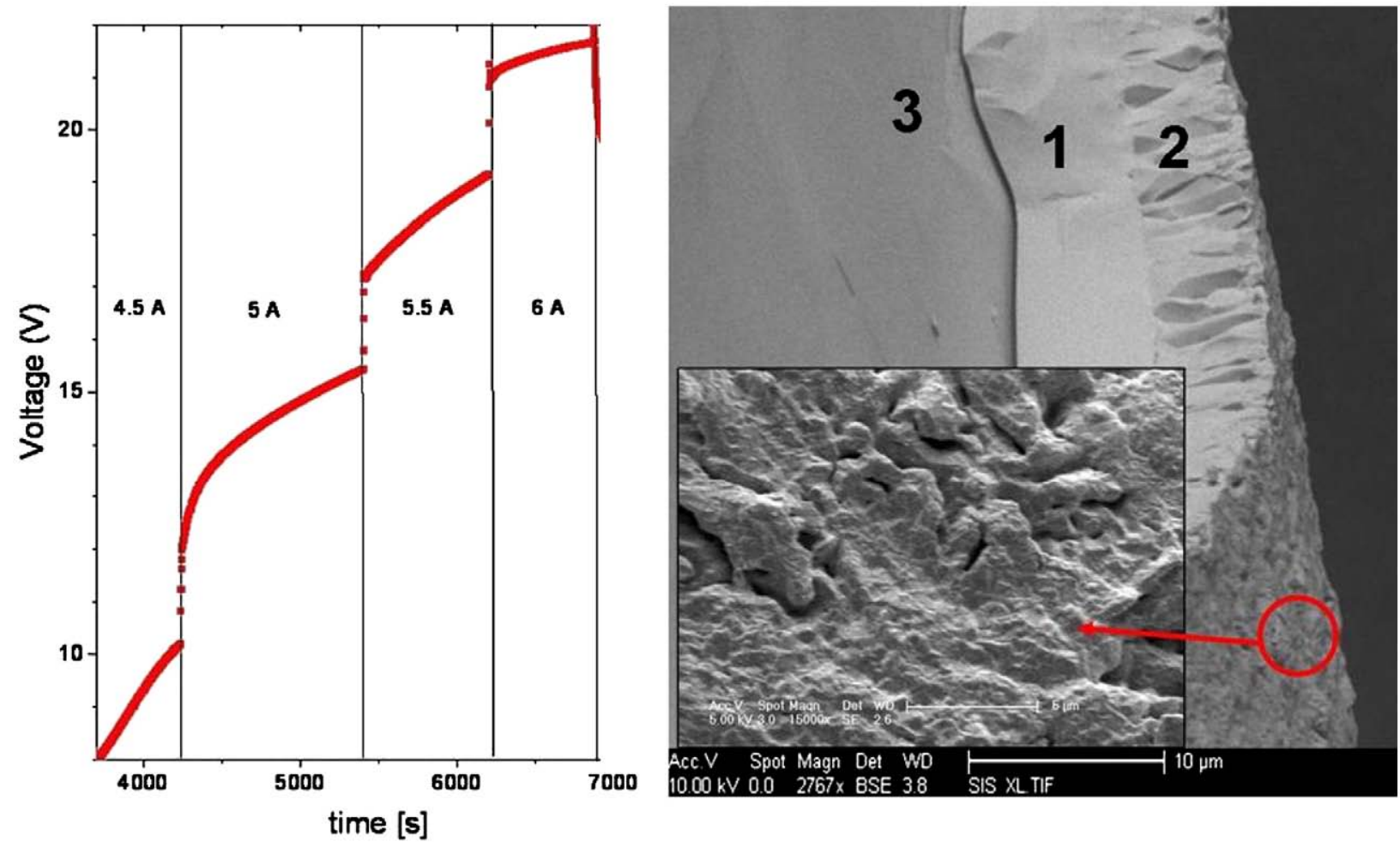

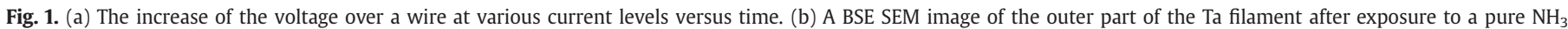
atmosphere. The inset is a SEM picture of the wire surface, micro-cracks are present.

the formation of $\mathrm{N}_{2}$ molecules during cooling of the wires. The solubility of $\mathrm{N}$ atoms decreases so fast (caused by the cooling of the wires) that they do not have enough time to diffuse to the filament surface before recombining to form possibly $\mathrm{N}_{2}$ gas. The pressure caused by the $\mathrm{N}_{2}$ gas formation during the decrease in temperature in the Ta wire may create micro cracks in the outer part of the filaments (where the temperature drop is the fastest and the $\mathrm{N}$ concentration the largest).

\subsection{Effect of ammonia combined with silane}

The voltage over the filaments was also monitored when exposed to a combined $\mathrm{NH}_{3}$ and silane $\left(\mathrm{SiH}_{4}\right)$ atmosphere, using $\mathrm{SiN}_{\mathrm{x}}$ deposition
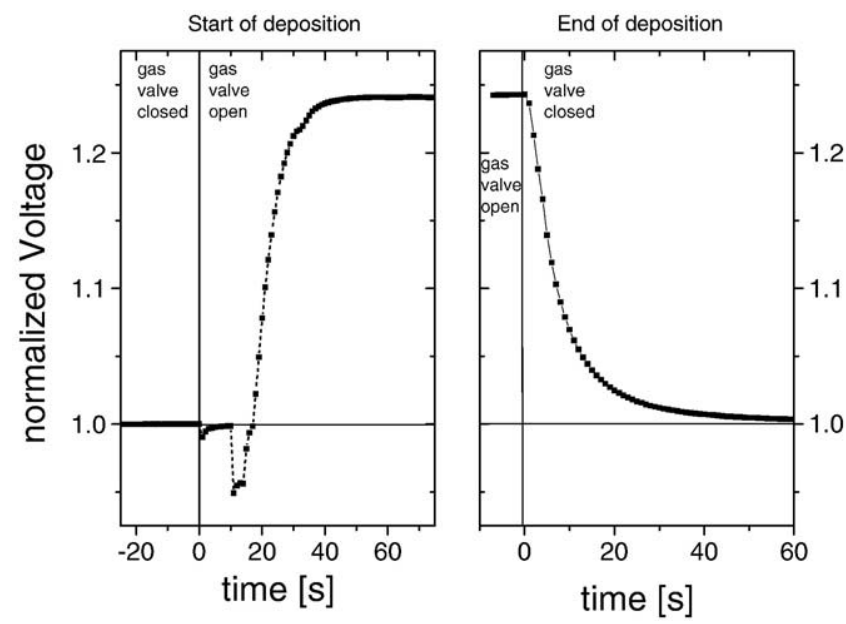

Fig. 2. The normalized voltage of a Ta filament before, during and after a $\operatorname{SiN}_{\mathrm{x}}$ deposition. conditions [9]. Fig. 2 presents the normalized voltage around the start and the end of a $\mathrm{SiN}_{\mathrm{x}}$ deposition. Once the source gasses reach the filaments the expected decrease in resistance (caused by a decrease in temperature) occurs. Shortly after which an increase in voltage of over $25 \%$ takes place. This increase is probably caused by dissolved $\mathrm{N}$ and $\mathrm{Si}$ atoms which increase the resistance. After shutting down the gas inlet valve the wire resistance recovers to the pre-deposition values (within $0.5 \%$ ) after $60 \mathrm{~s}$. This complete recovery indicates the absence of compositional modifications of the wire during the deposition. Optical micrographs shown in Fig. 3(a) and (b) reveal that $\mathrm{SiN}_{\mathrm{x}}$ films are deposited at the "cold" spots of the wires (near the electrical contacts). Clearly noticeable are the 5 deposited $\operatorname{SiN}_{\mathrm{x}}$ films, corresponding to the $5 \mathrm{SiN}_{\mathrm{x}}$ runs the wire was employed for. In contrast, no deposition occurred on the "hot", central part of the filaments as shown in Fig. 3(c) and (d).

\subsection{Effect of ammonia combined with methane}

Fig. 4 (a) shows an optical micrograph of a filament exposed to a mixed $\mathrm{NH}_{3}$, methane $\left(\mathrm{CH}_{4}\right)$, and $\mathrm{H}_{2}$ atmosphere as used for CNT deposition [13]. After the deposition, the filaments were golden in colour and highly brittle. The outer part of the Ta wires reveals structural changes and the Ta bulk shows that grains are present with a size of about $20 \mu \mathrm{m}$. At the grain boundaries a material similar in optical contrast to that on the outer part of the wire seems to be present. A XRD spectrum of the outer shell of the wire is shown in Fig. 4(b). The peaks show a perfect match with crystalline $\mathrm{TaC}_{0.275} \mathrm{~N}_{0.218}$ [14,15], indicating that this phase formed at the surface of the filament. Since it may be expected that the material on the grain boundaries is also $\mathrm{TaC}_{0.275} \mathrm{~N}_{0.218}$, it indicates that both $\mathrm{N}$ and $\mathrm{C}$ dissolve in the Ta filaments along the grain boundaries. From this analysis it is not clear whether these structures are formed during the deposition process or during the cool down period. 


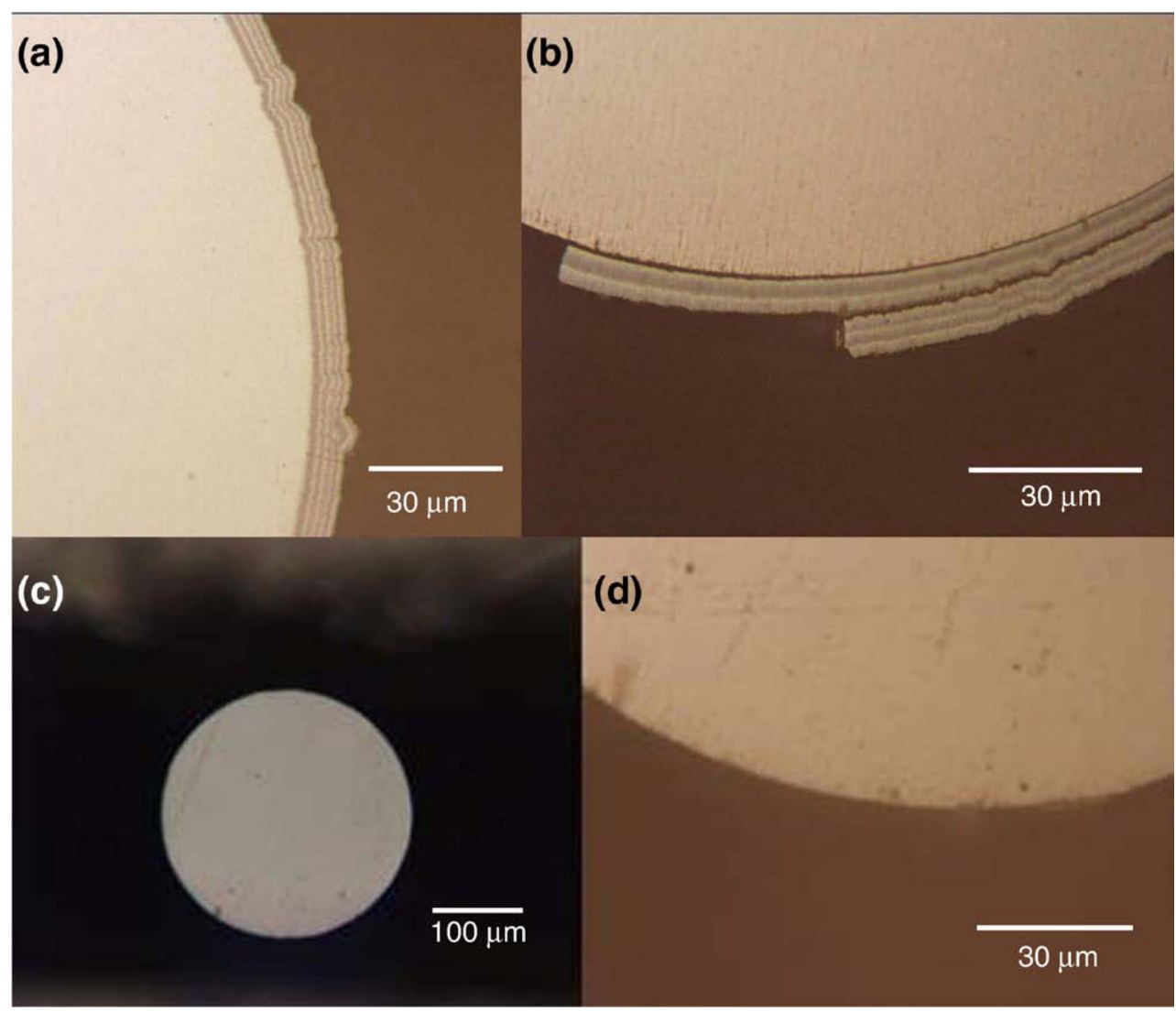

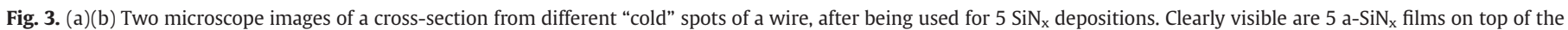
filament. (c)(d) Microscope image of a cross-section from a "hot" spot of a wire after being used for 5 SiN $_{\mathrm{x}}$ depositions. No structural modifications are visible.

To investigate whether an annealing step can remove the $\mathrm{TaC}_{0.275} \mathrm{~N}_{0.218}$ phase, the wires were annealed for $45 \mathrm{~min}$ at $2000{ }^{\circ} \mathrm{C}$ in vacuum. An optical micrograph shown in Fig. 5(b) reveals the internal structure of the annealed filament. The affected part of the wires has extended further into the bulk and has separated in $\mathrm{Ta}, \mathrm{Ta}_{2} \mathrm{C}$ and possibly still some $\mathrm{TaC}_{0.275} \mathrm{~N}_{0.218}$ regions as deduced from the XRD spectrum shown in Fig. 5(a). Furthermore, the size of the Ta grains has increased to a few hundred $\mu \mathrm{m}$. From these experiments it cannot be determined if this phase separation is already present at elevated temperatures or is created during the cooldown of the wires.

\section{Conclusions}

The exposure of Ta filaments in a HWCVD reactor to a pure $\mathrm{NH}_{3}$ ambient affects the resistance of the wires. For filament temperatures below $1950{ }^{\circ} \mathrm{C}$, the resistance increases with time, probably due to
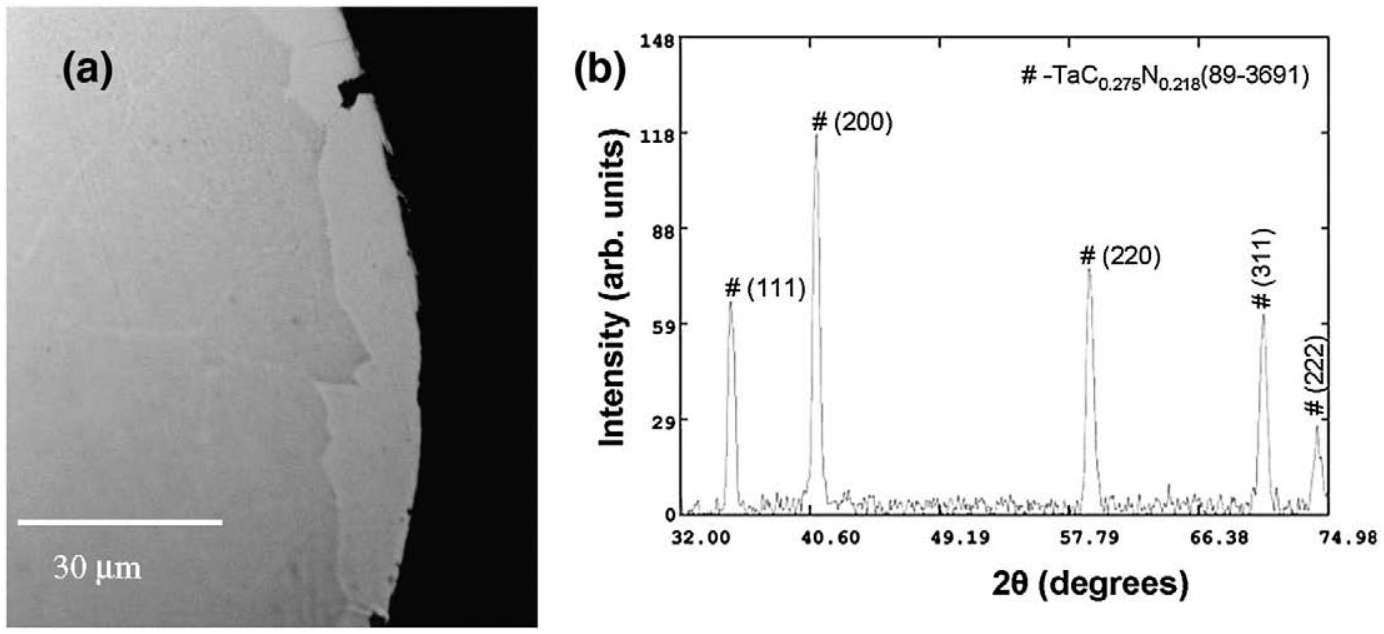

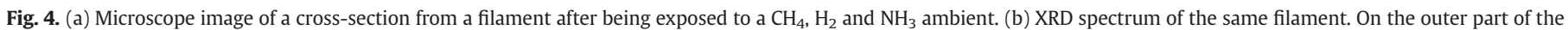
filament crystalline $\mathrm{TaC}_{0.275} \mathrm{~N}_{0.218}$ structures are present. The numbers indicate the reference spectrum in the international XRD database. 


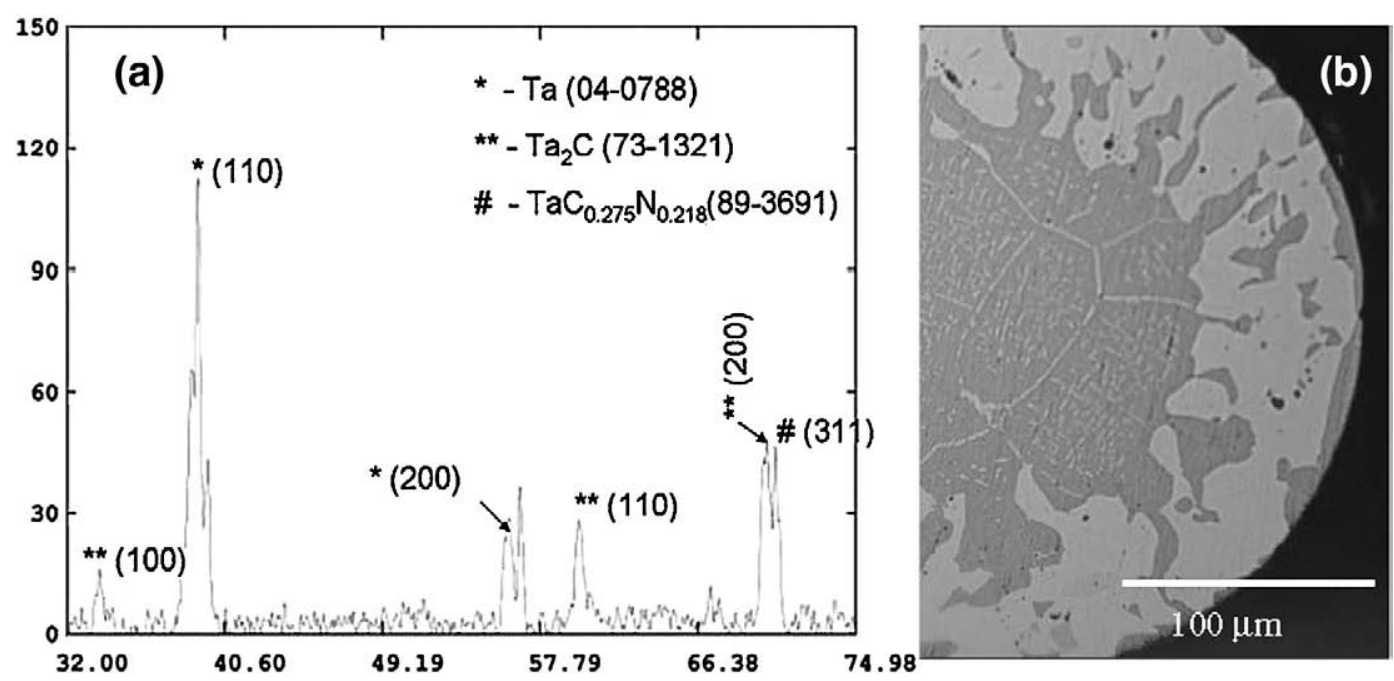

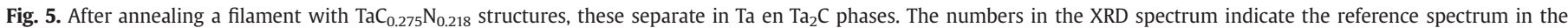
international XRD database.

inward diffusion of $\mathrm{N}$ atoms. Exposure of the filaments to a mixed $\mathrm{SiH}_{4}$ and $\mathrm{NH}_{3}$ atmosphere (under $\mathrm{SiN}_{\mathrm{x}}$ deposition conditions) does not affect the centre, "hot" part of the filaments. Only at the "cold" parts near the electrical contact deposited $\mathrm{SiN}_{\mathrm{X}}$ films are observed. XRD and cross-section microscope images reveal that in a $\mathrm{CH}_{4}, \mathrm{H}_{2}$ and $\mathrm{NH}_{3}$ ambient $\mathrm{TaC}_{0.275} \mathrm{~N}_{0.218}$ is formed on the outer part of the filament. Annealing of these filaments at $2000{ }^{\circ} \mathrm{C}$ causes the $\mathrm{TaC}_{0.275} \mathrm{~N}_{0.218}$ structures to separate mainly into $\mathrm{Ta}$ and $\mathrm{Ta}_{2} \mathrm{C}$ phases.

\section{References}

[1] J. Doyle, R. Robertson, G.H. Lin, M.Z. He, A. Gallagher, J. Appl. Phys. 64 (1988) 3215. [2] H.L. Duan, G.A. Zaharias, S.F. Bent, Mater. Res. Soc. Symp. Proc. 715 (2002) A15.5.1. [3] J.K. Holt, M. Swiatek, D.G. Goodwin, H.A. Atwater, J. Appl. Phys. 92 (2002) 98.
[4] D. Grunski, B. Schroeder, M. Scheib, R. Merz, W. Bock, C. Wagner, Thin Solid Films $516(2008) 818$

[5] D. Knoesen, C. Arendse, S. Halindintwali, T. Muller, Thin Solid Films 516 (2008) 822

[6] C.H.M. van der Werf,H. Li, V.Verlaan, C.J. Oliphant, R. Bakker, Z.S. Houweling and R.E.I. Schropp. This conference.

[7] H. Yokomichi, A. Masuda, N. Kishimoto, Thin Solid Films 395 (2001) 249.

[8] S. Mitra, R. Deshpande, T. Hanrath, J. Hartman, Thin Solid Films 430 (2003) 300.

[9] V. Verlaan, Z.S. Houweling, C.H.M. Van der Weg, I. Romijn, A. Weeber, H. Goldbach, and R.E.I. Schropp. Thin Solid Films 516 (2008) 533.

[10] F. Liu, S. Ward, B. Gedvillas, Q. Wang, E. Sanchez, S. Wang, J. Appl. Phys. 96 (2006 2973.

[11] C.S. Cojocaru, D. Kim, D. Pribat, J.E. Bouree, Thin Solid Films 501 (2006) 227.

[12] R.E.I. Schropp, K.F. Feenstra, E. Molenbroek, H. Meiling, J.K. Rath, Philos. Mag., B 76 (1997) 309.

[13] Z.S. Houweling, V. Verlaan, G.T. ten Grotenhuis and R.E.I. Schropp. This Conference.

[14] Y. Chang, J. Wu, P. Chang, H. Chiu, J. Mater. Chem. 13 (2003) 365.

[15] Y.V.Zaulychny, A.K. Sinelnichenko, A.Y. Garmash, O.Y. Khyzhun, Phys. Chem. Solids 6 (2005) 529. 